\title{
High-Latitude Nitric Oxide in the Lower Thermosphere
}

\author{
J.-C. GÉRARD \\ Laboratory for Atmospheric and Space Physics, University of Colorado, Boulder. Colorado 80309 \\ C. A. BARTH \\ Department of Astro-Geophysics and Laboratory for Atmospheric and Space Physics \\ University of Colorado, Boulder, Colorado 80309
}

\begin{abstract}
High-latitude observations of fluorescent nitric oxide gamma bands were made before and during a strong magnetic storm with the Ogo 4 ultraviolet spectrometer. Brightness measurements of the (1-0) gamma band of nitric oxide indicate a slow buildup of NO during the disturbed period. The NO column density reaches a value as high as a factor of 8 greater than the mid-latitude value and shows no correlation with the brightness of the instantaneous aurora. A time-dependent model calculation indicates that the ionization and dissociation of $\mathrm{N}_{2}$ by auroral electrons can increase the NO and $N\left({ }^{4} S\right)$ densities. This increase is dependent on the intensity and duration of the auroral precipitation and on the branching ratio of $\mathrm{N}\left({ }^{2} D\right)$ production by dissociation of $\mathrm{N}_{2}$. A steady state is not reached for $\mathrm{NO}$ until $10^{5} \mathrm{~s}$ in an aurora characterized by an energy flux of $10 \mathrm{ergs} / \mathrm{cm}^{2} \mathrm{~s}$. In that case the NO equilibrium density at $110 \mathrm{~km}$ ranges between $3 \times 10^{8}$ and $6 \times 10^{8} \mathrm{~cm}^{-3}$, depending on the model adopted. Dissociation by the solar ultraviolet radiation competes with horizontal and vertical transport as a loss process for the nitric oxide produced by the aurora. A high $\mathrm{NO}^{+} / \mathrm{O}_{2}{ }^{+}$ratio is to be expected in the period following a strong auroral precipitation.
\end{abstract}

\section{INTRODUCTION}

Rocket and satellite measurements of the intensity distribution of the nitric oxide gamma bands in the dayglow have been used successfully to determine the density and distribution of thermospheric NO at middle and low latitudes. Current theoretical models can account for the observed density of nitric oxide by assuming that $\mathrm{NO}$ is produced by the reaction of $\mathrm{O}_{2}$ with atomic nitrogen in the ground state $\mathrm{N}\left({ }^{4} S\right)$ and in the metastable state $\mathrm{N}\left({ }^{2} D\right)$ [Norton and Barth, 1970; Oran et al., 1975; Rusch et al., 1975]. The production of nitrogen atoms results from the direct dissociation of $\mathrm{N}_{2}$ as well as from charge transfer reactions of $\mathrm{O}^{+}$and $\mathrm{N}_{2}{ }^{+}$with ambient neutral atoms and molecules followed by dissociative recombination of $\mathrm{NO}^{+}$. The energy necessary to partly dissociate and ionize the neutral atmosphere is provided by the solar ultraviolet radiation.

In the last few years, various observations have indicated that the abundance of NO increases at high latitudes and that ionization by auroral particles may play an important role in the chemistry of N and NO. Recently, satellite measurements of resonance scattering of the NO gamma bands at high latitudes have been reported by Rusch and Barth [1975]. They found the NO concentration, on the average, to be 3-4 times higher in the polar region than at mid-latitudes and variable in time and space. Their measurements also indicated that the nitric oxide enhancement is not confined to the auroral oval but extends poleward and equatorward.

In this paper we analyze Ogo 4 twilight spectra of the NO gamma bands taken at high latitudes just before and during the geomagnetic storm period October 28 through November 6,1968 . Occasionally, IBC II sunlit auroras were observed, as evidenced by the brightening of the other auroral features. Even in such circumstances the nitric oxide column density remains less than $10^{15}$ molecules $/ \mathrm{cm}^{2}$, corresponding to an enhancement of less than a factor of 10 over low-latitude values. We investigate whether auroral activity increases the density of NO at high latitudes. Since the buildup of NO is

Copyright (C) 1977 by the American Geophysical Union. very slow, a time-dependent approach is necessary to model the behavior of nitric oxide in the aurora. The model developed here predicts NO density enhancements compatible with the Ogo 4 observations and indicates that the atomic nitrogen density increases significantly at low altitudes through auroral precipitation. This paper does not address itself to the results of mass spectrometer measurements in the aurora. That problem has recently been discussed by Hyman et al. [1976].

\section{Observations}

Spectra of the ultraviolet airglow were obtained between August 1967 and January 1969 by the University of Colorado ultraviolet spectrometer on board the Ogo 4 satellite. In particular, twilight measurements of the nitric oxide gamma bands were made at different latitudes in a band $85^{\circ}$ on either side of the equator. The NO gamma bands are excited by resonance scattering of sunlight in the wavelength region 2100-2500 $\dot{A}$. During the period October 26 to November 6, 1968, the spacecraft crossed the evening terminator in the southern hemisphere and the morning terminator in the northern hemisphere. The geomagnetic latitude of the twilight observations varied between $85^{\circ}$ and $37^{\circ}$, but only data gathered between the pole and the equatorward boundary of the auroral oval were considered for this analysis.

This period of time is of special interest, since the period October 20-28 was magnetically very quiet $(K p \leq 3)$ but was suddenly followed by a sequence of strong polar substorms. The activity culminated on November 1 , when $K p$ reached a value of 8 . The global geomagnetic storm which resulted was the greatest in 1968. Data were collected during the whole period except for two gaps on October 27 and November 2 and 3 due to the spacecraft mode of operation.

The emission of the NO $\gamma(1-0)$ band at $2150 \AA$ was deduced. from the observed intensity by using the preflight calibration of the instrument. At twilight the signal is due to the sum of resonance scattering of nitric oxide above the shadow height and the residual contribution of Rayleigh scattering from the lower atmosphere. In Figure $1 a$ the NO $\gamma(1-0)$ intensity obtained after subtracting the background is plotted versus 

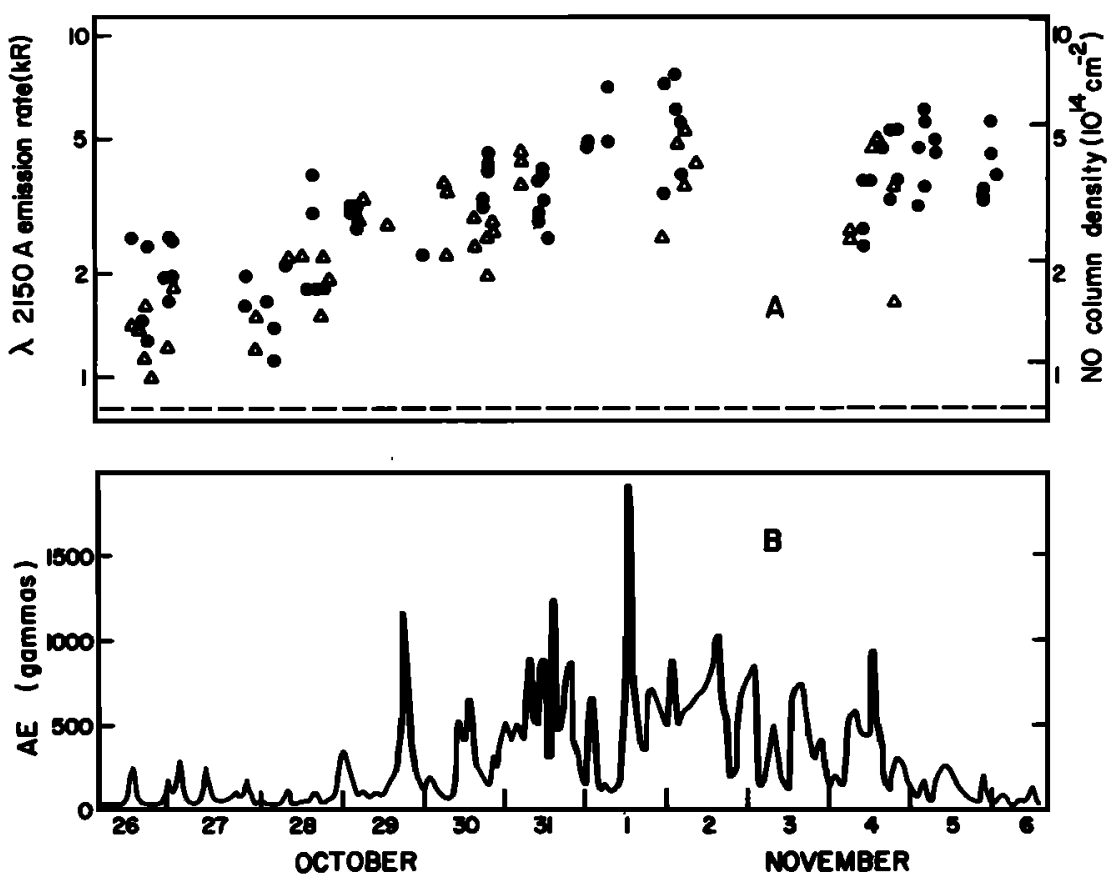

Fig. 1. (a) Emission rate of the NO $\gamma(1-0)$ band in the high-latitude twilight. Solid circles indicate morning twilight, and triangles indicate evening twilight. The dashed line indicates the average intensity observed at mid-latitudes with the same instrument. (b) A uroral electrojet index $A E$ (hourly average).

time for solar zenith angles (SZA) ranging from $93^{\circ}$ to $96^{\circ}$, which correspond to shadow heights between 65 and $90 \mathrm{~km}$. Evening and morning twilights are shown together, although different symbols have been used for each. The average midlatitude value of $0.75 \mathrm{kR}$, measured by Rusch [1973] with the same instrument, is indicated by a dashed line for comparison.

The emission rate $4 \pi I$ of the (1-0) band is converted into a NO column density $\eta$ by the relationship $4 \pi I=g \eta$, where $g$ is the emission rate factor. A column density scale is plotted at the right of Figure $1 a$ by using $g=8.2 \times 10^{-8}$ photon/molecule $s$ for an optically thin atmosphere [Cravens, 1976]. This value is about twice as large as Pearce's [1969] result but is in agreement with earlier values [Barth. 1966]. Figure $1 b$ shows the variation of the hourly auroral electrojet index $A E$ for the period of time considered here [Allen et al., 1973]. Several conclusions can be drawn from this figure.

1. The amount of nitric oxide in the atmosphere is greater at high latitudes than at mid-latitudes, even in magnetically quiet periods.

2. The column density gradually builds up and is enhanced by a factor of 4 during strong auroral activity. If the vertical distribution is the same as that at mid-latitudes, the NO density at $110 \mathrm{~km}$ varies between 0.9 and $4 \times 10^{8} \mathrm{~cm}^{-3}$.

3. There is no systematic difference in the NO density between the morning and evening twilights, although they occur in different hemispheres.

4. The amount of nitric oxide slowly decreases during the recovery phase of the storm.

On several occasions, sunlit auroras were seen in the field of view of the instrument at twilight as indicated by the $\mathrm{N}_{2}$ Lyman-Birge-Hopfield and [O I] $\lambda 1356-\AA$ emissions. In Figure 2 the intensity of the NO $\gamma(1-0)$ band is plotted versus the [O I] $\lambda 1356-\bar{A}$ emission rate for SZA between $95^{\circ}$ and $96^{\circ}$. There is no systematic relationship between the brightness of the two emission features, although the $\lambda 1356-\AA$ emission, which is mainly excited by auroral secondary electrons, is a good indicator of the intensity of the auroral precipitation. The highest $\bar{\lambda} 1356-\bar{A}$ intensity is of the order of $2 \mathrm{kR}$, corresponding to an $\mathrm{N}_{2}{ }^{+} \lambda 3914-\dot{\mathrm{A}}$ emission rate of about $25 \mathrm{kR}$, using the ratio measured by Miller et al. [1968]. Thus although the amount of nitric oxide at high latitudes is controlled by the auroral activity, there is no direct relationship to the instantaneous auroral brightness. This is of importance when discussing the auroral nitric oxide chemistry. In the next section we shall investigate whether the auroral precipitation enhances the amount of nitric oxide in the high-latitude atmosphere. This requires solving the time-dependent continuity equation for ions and odd nitrogen species.

\section{The Auroral Chemistry Model}

In order to compare the preceding results with theoretical calculations of the NO density in the aurora a time-dependent calculation of the auroral composition has been carried out.

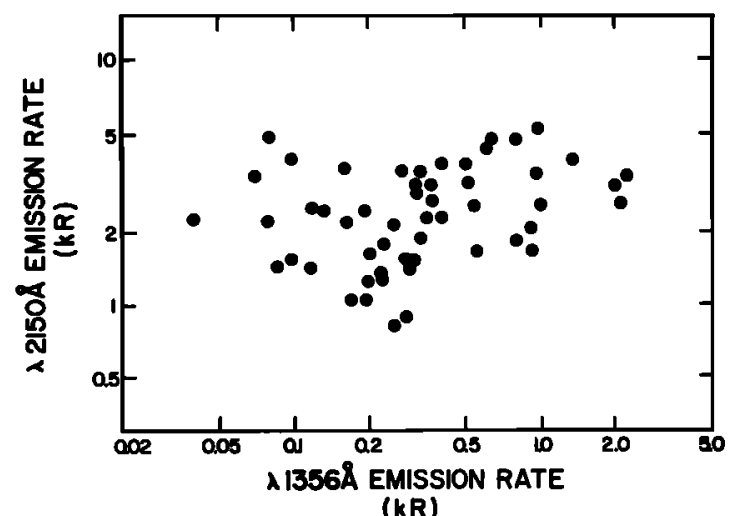

Fig. 2. Intensity of the NO $\gamma(1-0)$ band in the high-latitude twilight versus the intensity of the $O$ I $\lambda 1356-\bar{A}$ emission. 
The background atmosphere of $\mathrm{N}_{2}, \mathrm{O}_{2}$, and $\mathrm{O}$ is taken from Jacchia [1971] for an exospheric temperature of $1100^{\circ} \mathrm{K}$. The density of these species was held constant with respect to time or auroral activity, a reasonable assumption below $200 \mathrm{~km}$ as indicated by Hays et al. [1973]. Little is known about eddy diffusion above the turbopause and its role in vertical transport of NO at $110 \mathrm{~km}$. The effect of molecular diffusion is probably more important and has a characteristic lifetime, $\tau \simeq$ $H^{2} / D$, of the order of $2.4 \times 10^{5} \mathrm{~s}$. Neglecting diffusion in the following calculation is thus justified in the time scale of auroral events. The continuity equation

$$
\partial\left[N_{i}\right] / \partial t=P\left(N_{i}\right)-L\left(N_{i}\right)
$$

where $P$ and $L$ are the total production and loss rates of species $N_{i}$, respectively, is solved simultaneously for $\mathrm{NO}^{+}$, $\mathrm{O}_{2}{ }^{+}, \mathrm{N}_{2}{ }^{+}, \mathrm{O}^{+}, \mathrm{N}^{+}$, electrons, $\mathrm{N}\left({ }^{4} S\right), \mathrm{N}\left({ }^{2} D\right)$, and $\mathrm{NO}$. The list of important reactions and rate coefficients is given in Table 1. We assume that dissociative recombination, $\mathrm{NO}^{+}+e$, yields a fraction, $f_{1}=80 \%$, of $\mathrm{N}\left({ }^{2} D\right)$ atoms (D. Kley et al., unpublished manuscript, 1976). No experimental determination exists for the branching ratios of the other reactions producing nitrogen atoms. In this model we assume an efficiency $f_{3}$ of $100 \%$ for the production of $\left.\mathrm{N}^{2} D\right)$ by the reactions $\mathrm{N}_{2}{ }^{+}+\mathrm{O}$ and $\mathrm{N}^{+}+\mathrm{O}_{2}$. The reaction between $\mathrm{O}^{+}$and $\mathrm{N}_{2}$ is not energetically able to yield $N\left({ }^{2} D\right)$ atoms.

Since the electron temperature is not calculated in the model, the temperature dependence of dissociative recombination coefficients is estimated by using a $T^{-1}$ dependence. The value at $300^{\circ} \mathrm{K}$ [Biondi, 1969] is compatible with reçent laboratory determinations and is a satisfactory approximation for our purpose. As will be discussed later, reaction (R13) may be an important loss process for $\mathrm{O}_{2}{ }^{+}$ions. Calculations by Watson et al. [1967] indicate that about $40 \%$ of the $\mathrm{O}_{2}{ }^{+}$may be produced in the $a^{4} \Pi_{u}$ state. For the sake of simplicity we assume that all the $\mathrm{O}_{2}{ }^{+}$ions are in the ground state, and the rate coefficient is chosen accordingly [Lindinger et al., 1975]. The value of $1.6 \times 10^{-12} \mathrm{~cm}^{3} \mathrm{~s}^{-1}$ used for the deactivation coefficient of $\mathrm{N}\left({ }^{2} D\right)$ by atomic oxygen (reaction (R17)) is compatible with the analysis of the $N\left({ }^{2} D\right)$ nightglow when a production efficiency of $80 \%$ of $\mathrm{N}\left({ }^{2} D\right)$ by $\mathrm{NO}^{+}$recombination is assumed [Torr et al., 1976]. This value is also in good agreement with a laboratory measurement by Davenport et al. [1976].

The ionization profile adopted here is deduced from the $\mathbf{N}_{2}{ }^{+}$ 入3914-Aं altitude distribution measured by Donahue et al. [1970] and scaled to various values of the precipitated energy flux. Since the shapes of the ionization cross sections of $\mathrm{N}_{2}, \mathrm{O}_{2}$, and $\mathrm{O}$ are similar [Kieffer and Dunn, 1966], production rates can be deduced from the $\lambda 3914-\AA$ volume emission rate scaled by the density of target particles and the magnitude of the relevant cross section [Vallance-Jones, 1974]. The value of 14 for the ratio of the $\mathrm{N}_{2}$ ionization cross section to the $\lambda 3914-\bar{A}$ excitation cross section for electron impact measured by Borst and Zipf [1970] is adopted. Consequently, the following equations are deduced for the volume production rates $\eta$ of individual ions by electron impact:

$$
\begin{aligned}
& \eta\left(\mathrm{N}_{2}{ }^{+}\right)=11 \eta(\lambda 3914) \\
& \eta\left(\mathrm{N}^{+}\right)=0.32 \eta\left(\mathrm{N}_{2}{ }^{+}\right) \\
& \eta\left(\mathrm{O}_{2}{ }^{+}\right)=0.94 \eta\left(\mathrm{N}_{2}{ }^{+}\right)\left(\left[\mathrm{O}_{2}\right] /\left[\mathrm{N}_{2}\right]\right) \\
& \eta\left(\mathrm{O}^{+}\right)=0.78 \eta\left(\mathrm{N}_{2}{ }^{+}\right)\left([\mathrm{O}] /\left[\mathrm{N}_{2}\right]\right)+0.49 \eta\left(\mathrm{O}_{2}{ }^{+}\right)
\end{aligned}
$$

where $\eta(\lambda 3914)$ is the volume emission rate of $\mathrm{N}_{2}{ }^{+} \lambda 3914-\AA$ photons. $\mathrm{N}\left({ }^{2} D\right)$ and $\mathrm{N}\left({ }^{4} S\right)$ atoms can be produced by the dissociation of $\mathrm{N}_{2}$ by electrons:

(R21) $\mathrm{N}_{2}+e_{\text {fast }} \stackrel{f_{2}}{\rightarrow} \mathrm{N}\left({ }^{2} D,{ }^{4} S\right)+\mathrm{N}\left({ }^{2} D,{ }^{4} S\right)+e_{\text {fast }}$

and

(R22) $\mathrm{N}_{2}+e_{\text {fast }} \rightarrow \mathrm{N}\left({ }^{2} D\right)+\mathrm{N}^{+}+e+e_{\text {fast }}$

The fraction $f_{2}$ of nitrogen atoms in the $\mathbf{N}\left({ }^{2} D\right)$ state produced by reaction ( $R 21)$ is unknown and is a parameter in this calculation. However, there are theoretical grounds for expecting $f_{2} \simeq 0.5$ [Oran et al., 1975]. We arbitrarily assume that

\begin{tabular}{|c|c|c|c|}
\hline No. & Reaction & $\begin{array}{l}\text { Rate Coefficient, } \\
\qquad \mathrm{cm}^{3} \mathrm{~s}^{-1}\end{array}$ & Reference \\
\hline $\begin{array}{l}\text { (R1) } \\
\text { (R2) } \\
\text { (R3) } \\
\text { (R4) } \\
\text { (R5) } \\
\text { (R6) } \\
\text { (R7) } \\
\text { (R8) }\end{array}$ & $\begin{array}{l}\mathrm{NO}^{+}+e^{\prime} \rightarrow \mathrm{N}\left({ }^{2} D, 4\right)+\mathrm{O} \\
\mathrm{N}_{2}^{+}+e \rightarrow \mathrm{N}\left({ }^{2} D\right)+\mathrm{N} \\
\mathrm{O}_{2}^{+}+e \rightarrow \mathrm{O}+\mathrm{O} \\
\mathrm{N}^{+}+\mathrm{O}_{2} \rightarrow \mathrm{O}_{2}^{+}+\mathrm{N}\left({ }^{2} D\right) \\
\mathrm{N}^{+}+\mathrm{NO} \rightarrow \mathrm{NO}^{+}+\mathrm{N}\left({ }^{4} S\right) \\
\mathrm{N}^{+}+\mathrm{O}_{2} \rightarrow \mathrm{NO}^{+}+\mathrm{O} \\
\mathrm{O}^{+}+\mathrm{N}_{2} \rightarrow \mathrm{NO}^{+}+\mathrm{N}\left({ }^{4} S\right) \\
\mathrm{O}^{+}+\mathrm{O}_{2} \rightarrow \mathrm{O}_{2}{ }^{+}+\mathrm{O}\end{array}$ & $\begin{array}{l}4.0 \times 10^{-7}(300 / T) \\
3.0 \times 10^{-7} \\
2.0 \times 10^{-7}(300 / T) \\
2.8 \times 10^{-10} \\
8.0 \times 10^{-10} \\
2.8 \times 10^{-10} \\
1.2 \times 10^{-12}(300 / T) \\
2.0 \times 10^{-11}(300 / T)^{04}\end{array}$ & $\begin{array}{l}\text { see text } \\
\text { see text } \\
\text { see text } \\
\text { Lindinger et al. }[1974] \\
\text { Goldan et al. }[1966] \\
\text { Lindinger et al. }[1974] \\
\text { Lindinger et al. }[1974] \\
\text { Lindinger et al. }[1974]\end{array}$ \\
\hline $\begin{array}{l}(\mathrm{R} 9) \\
(\mathrm{R} 10) \\
(\mathrm{R} 11) \\
(\mathrm{R} 12) \\
(\mathrm{R} 13) \\
(\mathrm{R} 14) \\
(\mathrm{R} 15) \\
(\mathrm{R} 16) \\
\text { (R17) }\end{array}$ & $\begin{array}{l}\mathrm{N}_{2}^{+}+\mathrm{O}^{\prime} \rightarrow \mathrm{NO}^{+}+\mathrm{N}\left({ }^{2} D,{ }^{4} S\right) \\
\mathrm{N}_{2}^{+}+\mathrm{O}_{2} \rightarrow \mathrm{O}_{2}^{+}+\mathrm{N}_{2} \\
\mathrm{~N}_{2}{ }^{+}+\mathrm{NO} \rightarrow \mathrm{NO}^{+}+\mathrm{N}_{2} \\
\mathrm{O}_{2}^{+}+\mathrm{N}_{2} \rightarrow \mathrm{NO}^{+}+\mathrm{NO} \\
\mathrm{O}_{2}^{+}+\mathrm{NO} \rightarrow \mathrm{NO}^{+}+\mathrm{O}_{2} \\
\mathrm{O}_{2}{ }^{+}+\mathrm{N}\left({ }^{4} S\right) \rightarrow \mathrm{NO}^{+}+\mathrm{O} \\
\mathrm{N}\left({ }^{2} D\right)+\mathrm{O}_{2} \rightarrow \mathrm{NO}+\mathrm{O} \\
\mathrm{N}\left({ }^{2} D\right)+e \rightarrow \mathrm{N}\left({ }^{4} S\right)+e \\
\mathrm{~N}\left({ }^{2} D\right)+\mathrm{O} \rightarrow \mathrm{N}\left({ }^{4} S\right)+\mathrm{O}\end{array}$ & $\begin{array}{l}1.4 \times 10^{-10}(300 / T)^{0.4} \\
6.0 \times 10^{-11} \\
3.3 \times 10^{-10} \\
3.0 \times 10^{-17} \\
4.4 \times 10^{-10} \\
1.8 \times 10^{-10} \\
5.0 \times 10^{-12} \\
2.0 \times 10^{-9} \\
1.6 \times 10^{-12}\end{array}$ & $\begin{array}{l}\text { McFarland et al. }[1974] \\
\text { Johnsen et al. }[1970] \\
\text { Fehsenfeld et al. }[1970] \\
\text { Norton and Barth }[1970] \\
\text { Lindinger et al. }[1975] \\
\text { Goldan et al. }[1966] \\
\text { Lin and Kaufman }[1971] \\
\text { Henry and Williams }[1968] \\
\text { Davenport et al. }[1976] \text { and } \\
\quad \text { Torr et al. }[1976]\end{array}$ \\
\hline $\begin{array}{l}(\mathrm{R} 18) \\
(\mathrm{R} 19) \\
(\mathrm{R} 20)\end{array}$ & $\begin{array}{l}\mathrm{N}\left({ }^{2} D\right)+\mathrm{NO} \rightarrow \mathrm{N}_{2}+\mathrm{O} \\
\mathrm{N}\left({ }^{4} S\right)+\mathrm{O}_{2} \rightarrow \mathrm{NO}+\mathrm{O} \\
\mathrm{N}\left({ }^{4} S\right)+\mathrm{NO} \rightarrow \mathrm{N}_{2}+\mathrm{O}\end{array}$ & $\begin{array}{l}7.0 \times 10^{-11} \\
2.4 \times 10^{-11} \exp (-3975 / T) \\
1.5 \times 10^{-12}(T)^{1 / 2}\end{array}$ & $\begin{array}{l}\text { Lin and Kaufman [1971] } \\
\text { Wilson [1967] } \\
\text { Phillips and Schiff [1962] }\end{array}$ \\
\hline
\end{tabular}
reaction (R22) produces only $\mathrm{N}\left({ }^{2} D\right)$ atoms. Since the total dissociation cross section of $\mathrm{N}_{2}$ by electrons has a peak value close to that of the ionization cross section [Winters, 1966], we

TABLE 1. Reactions and Rate Coefficients with References 


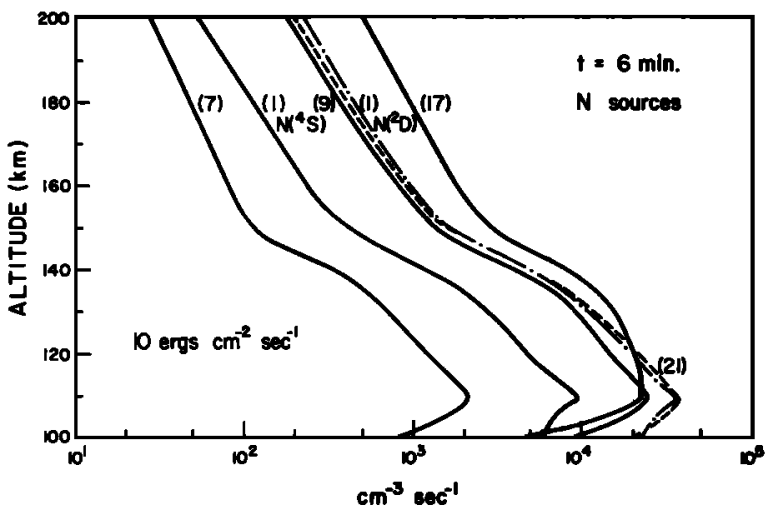

Fig. 3. Altitude distribution of the production rates of $\mathrm{N}\left({ }^{4} S\right)$ and $\mathrm{N}\left({ }^{2} D\right)$ after $6 \mathrm{~min}$ of $10 \mathrm{ergs} / \mathrm{cm}^{2} \mathrm{~s}$ electron precipitation. Numbers refer to the reactions listed in Table 1 and in the text.

assume that the dissociation rate of $\mathrm{N}_{2}$ and the production rate of $\mathrm{N}_{2}{ }^{+}$are equal. Consequently,

$$
\eta\left(\mathrm{N}^{4} S\right)=2\left(1-f_{2}\right) \eta\left(\mathrm{N}_{2}^{+}\right)
$$

and

$$
\begin{aligned}
\eta\left(\mathrm{N}^{2} D\right) & =2 f_{2} \eta\left(\mathrm{N}_{2}{ }^{+}\right)+\eta\left(\mathrm{N}^{+}\right) \\
& =\left(2 f_{2}+0.32\right) \eta\left(\mathrm{N}_{2}{ }^{+}\right)
\end{aligned}
$$

In order to investigate the effect of different auroral activity levels the ionization rates deduced from the $\lambda 3914-\dot{A}$ profile have been divided or multiplied by powers of 10 . The profile measured by Donahue et al. [1970] corresponds to an IBC I aurora with a slant $\lambda 3914-\AA$ intensity of $0.8 \mathrm{kR}$. By using a value of $810 \mathrm{R} \mathrm{ergs} / \mathrm{cm}^{2} \mathrm{~s}$ [Deehr and Egeland, 1972] for the efficiency of energy conversion into $\lambda 3914-\AA$. photons we found the energy flux of this aurora to be about $1 \mathrm{erg} / \mathrm{cm}^{2} \mathrm{~s}$.

The continuity equations have been solved numerically by the finite difference method for the nine time-dependent species. The time step of integration is calculated to insure charge and mass conservation and to provide the required accuracy of the results [Frederick, 1975]. The values of the initial ion and electron densities are the same as those described by Jones and Rees [1973]. The aurora is simulated by turning on abruptly the ionization profile described above. For simplicity we have assumed that the precipitation remains constant in flux and energy for periods exceeding $10^{6} \mathrm{~s}$. A fter a short time $(\simeq 100 \mathrm{~s})$, the calculated ion densities become independent of the initial conditions. The initial nitric oxide profile is that of Meira [1971] rescaled to account for the new value of the $g$ factor. The adopted $\mathrm{N}\left({ }^{4} S\right)$ profile is deduced from the average $\mathrm{NO} \gamma$ nightglow emission profile observed by the TD-1 ultraviolet experiment by using the method described by Gérard [1975]. However, the $\mathrm{N}\left({ }^{4} S\right)$ distribution has been normalized to the value of $7 \times 10^{6} \mathrm{~cm}^{-9}$ at $200 \mathrm{~km}$ deduced by Torr et al. [1975] from the analysis of the ion densities measured by the Atmosphere Explorer-C satellite. This implies a decrease by a factor of 2 of the TD-1 profile.

\section{Results}

Figure 3 illustrates the relative importance of the various mechanisms producing atomic nitrogen in a $10 \mathrm{ergs} / \mathrm{cm}^{2} \mathrm{~s}$ aurora for $f_{2}=0.5$. In this case, reactions (R1), (R9), and (R21) produce most of the $\mathrm{N}\left({ }^{2} D\right)$ at all altitudes. Reactions (R1) and (R21) dominate the $\mathrm{N}\left({ }^{4} S\right)$ production at low alti- tudes; the importance of reaction (R17) increases with altitude. In this model, $1.6 \mathrm{~N}\left({ }^{2} D\right)$ atoms are produced for each $\mathrm{N}\left({ }^{4} S\right)$ atom. The $\mathrm{N}\left({ }^{2} D\right)+\mathrm{O}_{2}$ reaction is the main source of NO below $140 \mathrm{~km}$, but above this altitude, $\mathrm{N}\left({ }^{4} S\right)+\mathrm{O}_{2}$ dominates the nitric oxide production.

Figure 4 shows the variation of the NO and $\mathrm{N}\left({ }^{4} S\right)$ densities at two altitudes as a function of time elapsed after a 10 $\mathrm{ergs} / \mathrm{cm}^{2} \mathrm{~s}$ aurora is abruptly turned on. At $110 \mathrm{~km}$ the nitric oxide starts increasing noticeably after $100 \mathrm{~s}$ at a rate depending on the value of $f_{2}$. A steady state is eventually reached after a time period depending also on $f_{2}$. This growth of nitric oxide is due to (1) the enhanced dissociation and ionization of $\mathrm{N}_{2}$ by auroral electrons increasing the $\mathrm{N}\left({ }^{2} D\right)$ production rate and (2) more NO molecules than $\mathrm{N}\left({ }^{4} S\right)$ atoms being produced in the aurora, although the loss rates of $\mathrm{NO}$ and $\mathrm{N}\left({ }^{4} S\right)$ are nearly equal. The $\mathrm{N}\left({ }^{4} S\right)$ density is more altered than the NO density and reaches a maximum of $1.5-3.5 \times 10^{7} \mathrm{~cm}^{-3}$ after $8 \times 10^{2}$ to $2 \times 10^{9} \mathrm{~s}$. This dramatic effect is due to the low value of the initial $N\left({ }^{4} S\right)$ density used in the model. Later the $N\left({ }^{4} S\right)$ decreases and finally stabilizes. The time variation of NO and $\mathrm{N}\left({ }^{4} S\right)$ can be adequately described at $110 \mathrm{~km}$ by the following simplified equations:

$$
\frac{\partial[\mathrm{NO}]}{\partial t}=P_{\mathrm{NO}}-\left\{k_{20}\left[\mathrm{~N}\left({ }^{4} S\right)\right]+k_{1 \mathrm{~s}}\left[\mathrm{O}_{2}{ }^{+}\right]+k_{1 \mathrm{~g}}\left[\mathrm{~N}\left({ }^{2} D\right)\right]\right\}[\mathrm{NO}]
$$

and

$$
\frac{\partial\left[\mathrm{N}\left({ }^{4} S\right)\right]}{\partial t}=P_{\left.\mathrm{N}^{4}{ }^{4}\right)}-k_{20}[\mathrm{NO}]\left[\mathrm{N}\left({ }^{4} S\right)\right]
$$

Since both $P_{\mathrm{N}(\text { 's) }}$ and $P_{\mathrm{No}}$ exceed the loss rate (essentially $k_{20}[\mathrm{NO}]\left[\mathrm{N}\left({ }^{4} S\right)\right]$ during the first minutes, both $\left[\mathrm{N}\left({ }^{4} S\right)\right]$ and [NO] increase with time. Consequently, since $P_{\mathrm{No}}$ and $P_{\left.\mathrm{N}_{(4}^{4} \mathrm{~S}\right]}$ are nearly constant after a few seconds, at a given time, $P_{\mathrm{N}^{4} \mathrm{~s}}$ $=L_{\mathrm{N}(\mathrm{s})}$, and $\left(\partial\left[\mathrm{N}\left({ }^{4} S\right)\right] / \partial t\right)$ is zero and then turns negative. At this moment, $(\partial[\mathrm{NO}] / \partial t)$ is still positive and [NO] continues to increase, although it is temporarily slowed somewhat by the $k_{20}[\mathrm{NO}]\left[\mathrm{N}\left({ }^{4} S\right)\right]$ term. Eventually, both densities will stabilize when $(\partial[\mathrm{NO}] / \partial t)=\left(\partial\left[\mathrm{N}\left({ }^{4} S\right)\right] / \partial t\right)=0$. At $150 \mathrm{~km}$ the $\mathrm{N}\left({ }^{4} S\right)$ density decreases with time because of the arbitrary choice of the initial profile used in the model and stabilizes after about $10^{5} \mathrm{~s}$. Above $150 \mathrm{~km}$ the NO production is mainly due to the $\mathrm{N}\left({ }^{4} S\right)+\mathrm{O}_{2}$ reaction. Therefore the NO density is largely independent of the intensity of precipitation and the value of $f_{2}$ and converges to the equilibrium density [NO] $=\left(k_{18} / k_{20}\right)\left[\mathbf{O}_{2}\right]$. If lower or higher values of initial $\mathrm{N}\left({ }^{4} S\right)$ density are used, the NO curve is nearly unchanged and the $\mathrm{N}\left({ }^{4} S\right)$ curves coincide after some time. Figures 5 and 6 show the altitude distribution of $\mathrm{NO}$ and $\mathrm{N}\left({ }^{4} S\right)$ at different times.

The influence of the intensity of auroral precipitation on nitric oxide is illustrated in Figure 7 for $f_{2}=0.5$. The growth rate of NO increases with increasing energy deposition at all altitudes. The level at which the NO density stabilizes depends on the auroral intensity. A weak subvisual aurora will have little effect on NO at $110 \mathrm{~km}$, whereas an IBC III aurora will double the amount of $\mathrm{NO}$ in about $1 \mathrm{~min}$.

Figure 8 shows the decay of NO and $\mathrm{N}\left({ }^{4} S\right)$ when the energy flux is reduced from 10 to $0.1 \mathrm{erg} / \mathrm{cm}^{2} \mathrm{~s}$. Nitric oxide shows virtually no decrease even after 1 day. $\mathrm{N}\left({ }^{4} S\right)$ reaches a steady state after about $20 \mathrm{~min}$ at $110 \mathrm{~km}$ and 8 hours at $150 \mathrm{~km}$. This long lifetime of NO, $\tau=\left(k_{20}\left[N\left({ }^{4} S\right)\right]\right)^{-1}$, results from the rapid depletion of $\mathrm{N}\left({ }^{4} S\right)$, which is less abundant than NO.

During the daytime, nitric oxide will be destroyed by the ultraviolet solar radiation $(\lambda<1900 \AA)$, essentially through 


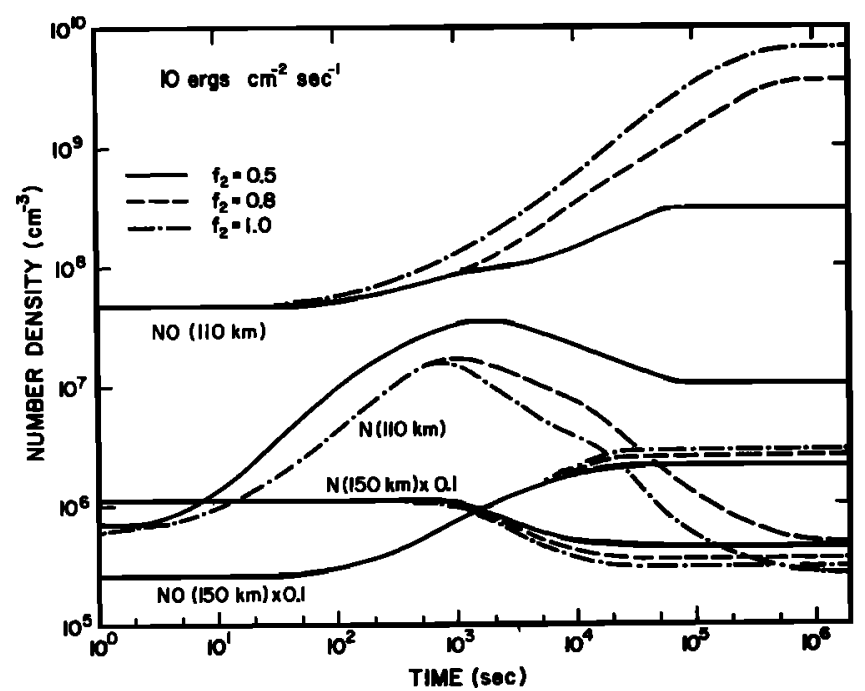

Fig. 4. Time variation of $\mathrm{NO}$ and $\mathrm{N}\left({ }^{\prime} S\right)$ densities at two altitudes for various values of the branching ratio $f_{2}$.

the predissociation of the $\delta$ bands at a rate of about $1.4 \times 10^{-5}$ $\mathrm{s}^{-1}$ [Cieslik and Nicolet, 1973]. The importance of this process will depend on the length of the day and, consequently, on the latitude and period of the year. The NO decay due to dissociation at $110 \mathrm{~km}$ is indicated by a dashed line in Figure 8 for a 6-hour day (early November at a latitude of $75^{\circ} \mathrm{N}$ ).

The influence of the past history of the aurora on the ion chemistry is illustrated in Figure 9, where the $\mathrm{NO}^{+}$and $\mathrm{O}_{2}{ }^{+}$ densities are plotted versus time during the growth and the decay of the aurora. The $\mathrm{NO}^{+} / \mathrm{O}_{2}{ }^{+}$ratio starts increasing $10^{2} \mathrm{~s}$ after the beginning of precipitation because of the effect of reaction (R/3). During the decay of the aurora the $\mathrm{NO}^{+} / \mathrm{O}_{2}{ }^{+}$ ratio reaches values of nearly 40 after $30 \mathrm{~s}$ and stabilizes at about 20 after $200 \mathrm{~s}$. If the 0.1-erg aurora had not been preceded by a stronger precipitation, the steady state ratio would be about 4 . To discuss the effect of the NO density on the $\mathrm{NO}^{+} / \mathrm{O}_{2}{ }^{+}$ratio, the following equation can be written when $\mathrm{NO}^{+}$is in a steady state:

$$
P_{\mathrm{NO}^{+}}=P_{\mathrm{NO}^{+}}+k_{19}\left[\mathrm{O}_{2}^{+}\right][\mathrm{NO}]=k_{1}\left[\mathrm{NO}^{+}\right]\left[N_{\mathrm{e}}\right]
$$

with the dominant terms

$$
P_{\mathrm{NO}^{+}}=k_{\mathrm{\theta}}\left[\mathrm{N}_{2}^{+}\right][\mathrm{O}]+k_{7}\left[\mathrm{O}^{+}\right]\left[\mathrm{N}_{2}\right]+k_{\mathrm{\theta}}\left[\mathrm{N}^{+}\right]\left[\mathrm{O}_{2}\right]
$$

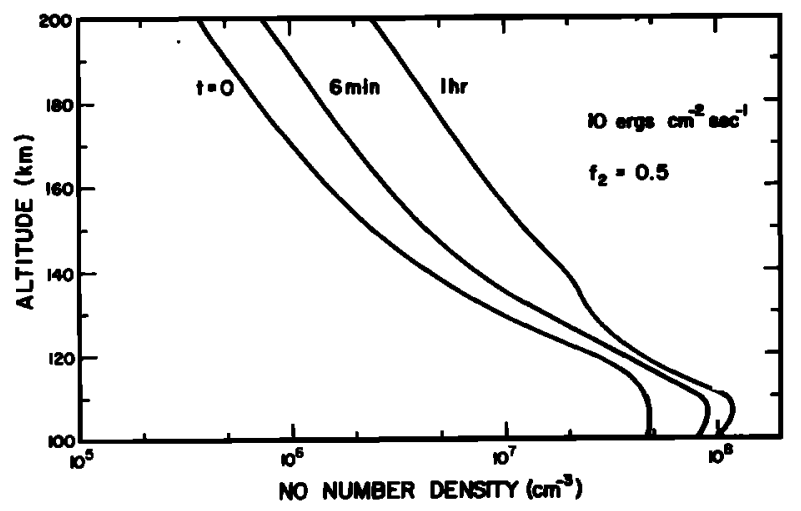

Fig. 5. Altitude distribution of nitric oxide for different times elapsed after the beginning of a $10 \mathrm{ergs} / \mathrm{cm}^{2} \mathrm{~s}$ electron precipitation.

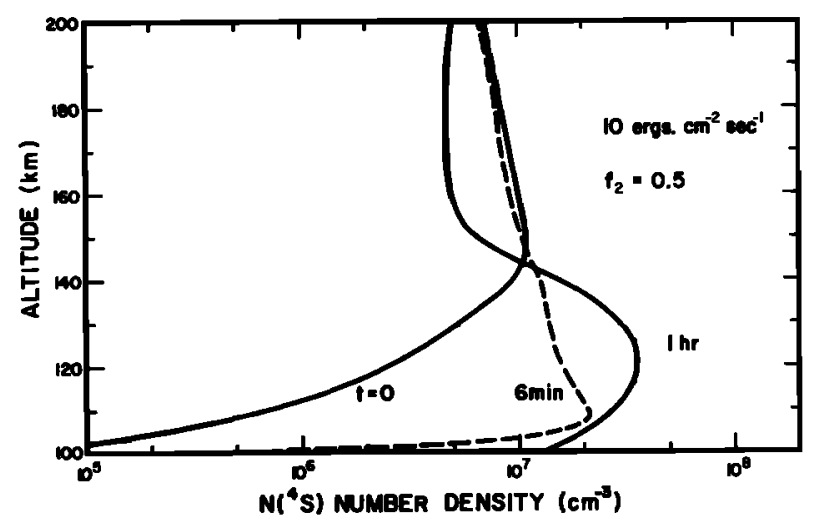

Fig. 6. Altitude distribution of atomic nitrogen for different times elapsed after the beginning of a $10 \mathrm{ergs} / \mathrm{cm}^{2} \mathrm{~s}$ electron precipitation.

Thus (4) and (5) yield the following expression for the $\mathrm{NO}^{+} / \mathrm{O}_{2}^{+}$ratio:

$$
R=\frac{\left[\mathrm{NO}^{+}\right]}{\left[\mathrm{O}_{2}^{+}\right]}=\frac{k_{13}}{k_{1} N_{e}}\left\{[\mathrm{NO}]+\frac{P_{\mathrm{NO}^{+}}}{k_{13}\left[\mathrm{O}_{2}^{+}\right]}\right\}
$$

which is an increasing function of the NO density. This shows that the $\left[\mathrm{NO}^{+}\right] /\left[\mathrm{O}_{2}{ }^{+}\right]$ratio is not related to the instantaneous energy precipitation but depends, through the NO density, on the past history of the aurora. These limitations must be taken into account when deriving NO densities from the ionic composition [Swider and Narcisi, 1974; Donahue et al., 1970].

\section{Discussion}

Our calculations indicate that a major effect of auroral precipitation is to increase the density of total odd nitrogen species in the $110-$ to $120-\mathrm{km}$ region. This is caused by the enhanced ionization and dissociation of $\mathrm{N}_{2}$ by auroral electrons which produce, directly or indirectly, $\mathrm{N}^{+}, \mathrm{NO}^{+}, \mathrm{N}\left({ }^{2} D\right)$, $\mathrm{N}\left({ }^{4} S\right)$, and NO. The increase of NO depends on the intensity and the duration of the precipitation. Any value between 0.5 and 1.0 of the parameter $f_{2}$ which describes the fraction of $\mathrm{N}\left({ }^{2} D\right)$ atoms produced by $\mathrm{N}_{2}$ dissociation is compatible with the observations. The observed nitric oxide increase is in agreement with the model, although direct comparison is precluded by the lack of data for the time variation of the flux and energy of electron precipitation. However, note that the NO column density predicted by the model for $f_{2}=0.5$ and a

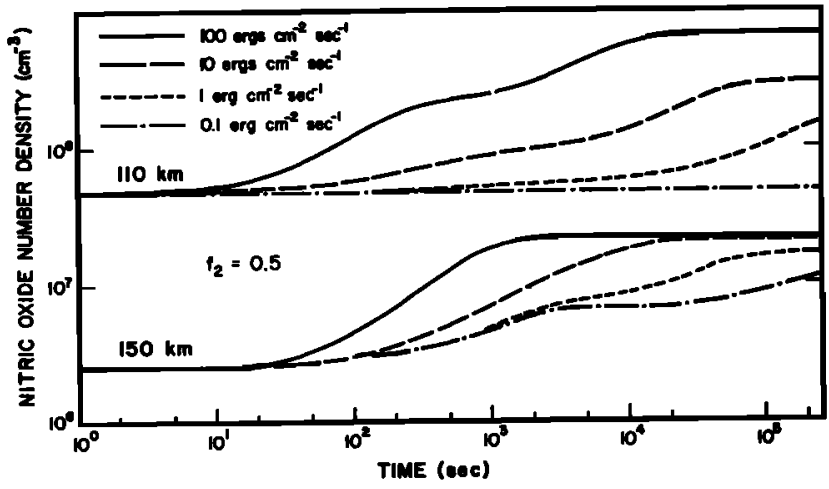

Fig. 7. Time variation of the nitric oxide density at two altitudes for different intensities of electron precipitation. 


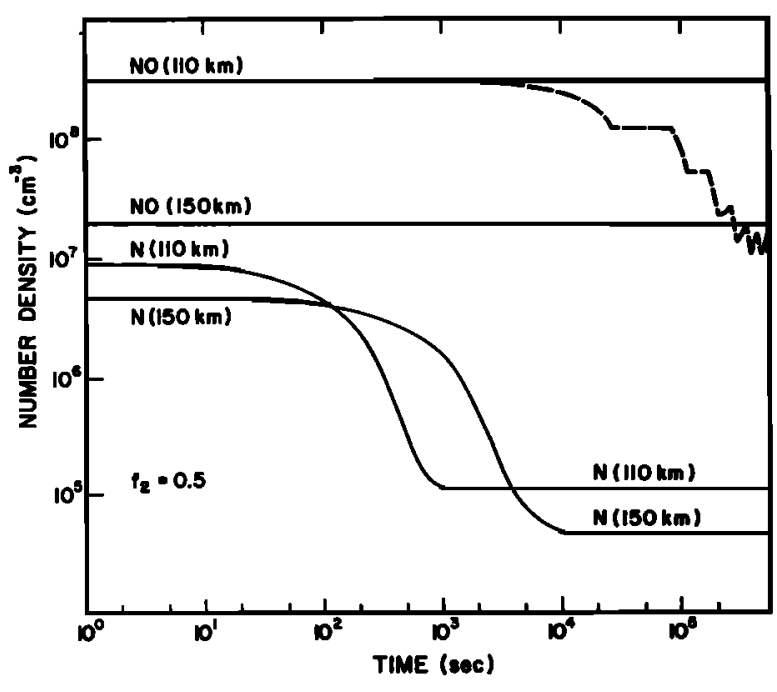

Fig. 8. Time variation of NO and $\mathrm{N}\left({ }^{4} S\right)$ densities at two altitudes when the precipitated energy flux decreases from 10 to $0.1 \mathrm{erg} / \mathrm{cm}^{2} \mathrm{~s}$ The dashed line indicates the effect of the dissociation of NO by solar ultraviolet radiation at $110 \mathrm{~km}$.

precipitated energy flux of $10 \mathrm{ergs} / \mathrm{cm}^{2} \mathrm{~s}$ is about $1 \times 10^{14} \mathrm{~cm}^{-2}$ after 1 hour and $7 \times 10^{14} \mathrm{~cm}^{-2}$ after more than 1 day. These values compare favorably with the Ogo 4 observations of 2-6 $\times 10^{14} \mathrm{~cm}^{-2}$ during the storm (Figure 1). A steady state is reached after a time that is dependent on the intensity of the precipitation, but this plateau is unlikely to be reached in a single auroral event, since bright auroral displays generally have characteristic times of the order of $10 \mathrm{~min}$ or less. The succession of auroras will progressively increase the NO density. In any case it appears that [NO] values in excess of $10^{10}$ $\mathrm{cm}^{-3}$ at $110 \mathrm{~km}$ will not be reached in any aurora.

The chemical decay of nitric oxide is very slow, since the $\mathbf{N}\left({ }^{4} S\right)$ density stabilizes at a low value soon after precipitation decreases. Other, probably more effective, loss mechanisms include (1) dissociation of nitric oxide by ultraviolet sunlight, (2) vertical transport by diffusion and winds, and (3) horizontal transport by winds. The chemical lifetime of nitric oxide is given by

$$
\left\{k_{20}\left[\mathrm{~N}\left({ }^{4} S\right)\right]+k_{19}\left[\mathrm{O}_{2}^{+}\right]\right\}^{-1}
$$

and is of the order of $3 \times 10^{5} \mathrm{~s}$ in the above example. The lifetime against dissociation is of the order of $\left(2 J_{\mathrm{NO}}\right)^{-1}$, since

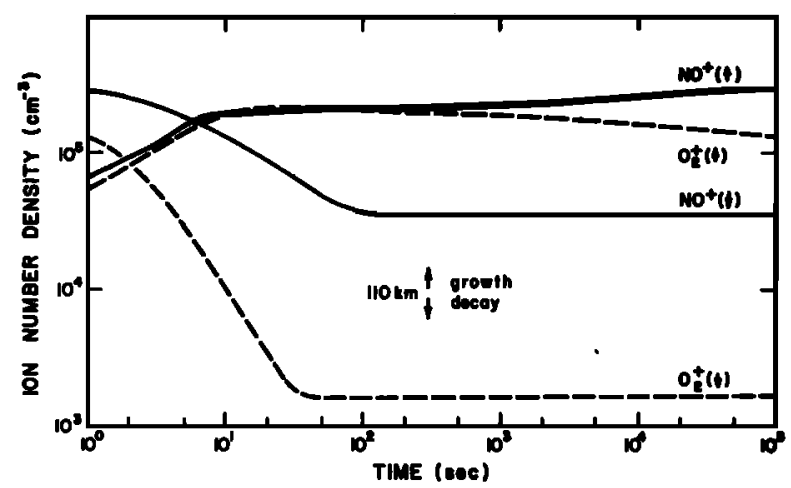

Fig. 9. Time variation of the $\mathrm{O}_{2}{ }^{+}$and $\mathrm{NO}^{+}$densities after a 10 $\mathrm{ergs} / \mathrm{cm}^{2} \mathrm{~s}$ precipitation is turned on (growth) or reduced by 2 orders of magnitude (decay). each nitric oxide dissociation leads to a new $N\left({ }^{4} S\right)$ atom which will eventually destroy another NO molecule. The effective lifetime for predissociation depends on the duration of the day and is of the order of $1.5 \times 10^{5} \mathrm{~s}$ for a 6-hour day. Vertical winds with velocities of a few meters per second can be generated above $150 \mathrm{~km}$ as a result of local heating by auroral particles and perpendicular electric fields [Hays et al., 1973]. Their effect on the vertical distribution of minor constituents has been discussed recently by Prasad and Furman [1975], who found that even wind velocities in excess of $10 \mathrm{~m} / \mathrm{s}$ have little effect on the altitude profile of nitric oxide below $160 \mathrm{~km}$.

\section{SUMMARY}

This present study shows that the nitric oxide density increases during auroral activity principally because the bombardment of the atmosphere by auroral electrons produces increased ionization. During the dissociative recombination of ionized nitric oxide, more $\mathrm{N}\left({ }^{2} D\right)$ than $\mathrm{N}\left({ }^{4} S\right)$ atoms are created. In the reaction of molecular oxygen, $\mathrm{N}\left({ }^{2} D\right)$ atoms produce nitric oxide, while $\mathbf{N}\left({ }^{4} S\right)$ atoms are the principal agent for destruction. The results of this model calculation show that the difference between the high-latitude and low-latitude production of nitric oxide is essentially the difference in the ionization rates of the two regions.

Acknowledgments. This work was supported by the National Aeronautics and Space Administration under grants NGR 06-003-127 and NGL 06-003-052. J.-C. Gérard's participation has been partially supported by a NATO fellowship.

The Editor thanks E. Oran and M. R. Torr for their assistance in evaluating this paper.

\section{REFERENCES}

Allen, J. H., C. C. Abston, and L. D. Morris, Auroral electrojet magnetic activity indices $A E(11)$ for 1968, World Data Center Rep. $A, U A G-29$, NOAA, Boulder, Colo., 1973.

Barth, C. A., Nitric oxide in the upper atmosphere, Ann. Geophys., 22, 198, 1966.

Biondi, M., Electron recombination and ion recombination, Can. J. Chem., 47, 1723, 1969.

Borst, W. L., and E. C. Zipf, Cross-section for $e^{-}$impact excitation of the $0,01 \mathrm{~N} \mathrm{~N}_{2}{ }^{+}$band for threshold to $3 \mathrm{keV}$, Phys. Rev., Sect. $A, 1$, 834, 1970.

Cieslik, S., and M. Nicolet, The aeronomic dissociation of nitric oxide, Planet. Space Sci., 21, 925, 1973.

Cravens, T. E., Nitric oxide gamma band emission rate factor, Planet. Space Sci., in press, 1977.

Davenport, J. E., T. G. Slanger, and G. Black, The quenching of $\mathrm{N}\left({ }^{2} D\right)$ by $\mathrm{O}\left({ }^{3} P\right), J$. Geophys. Res., $81,12,1976$.

Deehr, C. S., and A. Egeland, Auroral morphology, Ann. Geophys., 28, 415, 1972.

Donahue, T. M., E. C. Zipf, and T. D. Parkinson, Ion composition and ion chemistry in an aurora, Planet. Space Sci., 18, 171, 1970.

Fehsenfeld, F. C., D. B. Dunkin, and E. E. Ferguson, Rate constants for the reaction of $\mathrm{CO}_{2}^{+}$with $\mathrm{O}, \mathrm{O}_{2}$, and $\mathrm{NO} ; \mathrm{N}_{2}{ }^{+}$with $\mathrm{O}$ and $\mathrm{NO}$; and $\mathrm{O}_{2}{ }^{+}$with NO, Planet. Space Sci., 18, 1267, 1970.

Frederick, J. E., SIXBITD: A reaction kinetics computer code including vertical transport, description of numerical methods, and operation, technical report, Environ. Res. Lab., NOAA, Boulder, Colo., 1975.

Gérard, J.-C., Satellite observations of the nitric oxide nightglow, Geophys. Res. Lett., 2, 179, 1975.

Goldan, P. D., A. L. Schmeltekopf, F. C. Fehsenfeld, H. I. Schiff, and E. E. Ferguson, Thermal energy ion-neutral reaction rates, 2, Some reactions of ionospheric interest, J. Chem. Phys., 44, 4095, 1966.

Hays, P. B., R. A. Jones, and M. H. Rees, Auroral heating and the composition of the neutral atmosphere, Planet. Space Sci., 21, 559, 1973.

Henry, R. J. W., and R. E. Williams, Collision strengths and photoionization cross-sections for nitrogen, oxygen, and neon, Publ. Astron. Soc. Pac. 80, 669, 1968.

Hyman, E., D. J. Strickland, P. S. Julienne, and D. F. Strobel, Auroral NO concentrations?, J. Geophys. Res., 81, 4765, 1976. 
Jacchia, L. G., Revised static models of the thermosphere and exosphere with empirical temperature profiles, Spec. Rep. 332, Smithson. Astrophys. Observ., Cambridge, Mass., 1971.

Johnsen, R., H. L. Brown, and M. A. Biondi, Ion-molecule reactions involving $\mathrm{N}_{2}^{+}, \mathrm{N}^{+}, \mathrm{O}_{2}^{-+}$, and $\mathrm{O}^{+}$ions from $300^{\circ} \mathrm{K}$ to $\sim 1 \mathrm{eV}, J$. Chem. Phys., 52, 5080, 1970.

Jones, R. A., and M. H. Rees, Time dependent studies of the aurora, 1, Ion density and composition, Planet. Space Sci., 21, 537, 1973.

Kieffer, L. J., and G. H. Dunn, Electron impact ionization crosssection data for atoms, atomic ions, and diatomic molecules, 1 , Experimental data, Rev. Mod. Phys., 38, 1, 1966.

Lin, C. L., and F. Kaufman, Reactions of metastable nitrogen atoms, J. Chem. Phys., 55, 3760, 1971.

Lindinger, W., F. C. Fehsenfeld, A. L. Schmeltekopf, and E. E. Ferguson, Temperature dependence of some ionospheric ion-neutral reactions from $300^{\circ}$ to $900^{\circ} \mathrm{K}, J$. Geophys. Res. 79, 4753, 1974.

Lindinger, W., D. L. Albritton, F. C. Fehsenfeld, and E. E. Ferguson, Laboratory measurements of the ionospheric $\mathrm{O}_{2}{ }^{+}\left(X^{2} \Pi_{\varepsilon}\right)$ and $\mathrm{O}_{2}{ }^{+}$ $\left(a^{4} \Pi_{u}\right)$ reactions with NO, J. Geophys. Res., 80, 3725, 1975.

McFarland, M., D. L. Albritton, F. C. Fehsenfeld, E. E. Ferguson, and A. L. Schmeltekopf, Energy dependence and branching ratio of the $\mathrm{N}_{2}{ }^{+}+\mathrm{O}$ reaction, J. Geophys. Res., 79. 2925, 1974.

Meira, L. G., Jr., Rocket measurements of upper atmosphere nitric oxide and their consequences to the lower atmosphere, J. Geophys. Res.. 76, 202, 1971.

Miller, R. E., W. G. Fastie, and R. C. Isler, Rocket studies of far-UV radiation in an aurora, J. Geophys. Res., 73, 3353, 1968.

Norton, R. B., and C. A. Barth, Theory of nitric oxide in the earth's atmosphere, J. Geophys. Res., 75, 3903, 1970.

Oran, E. S., P. S. Julienne, and D. F. Strobel, The aeronomy of odd nitrogen in the thermosphere, J. Geophys. Res., 80, 3068, 1975.

Pearce, J. B., Nitric oxide gamma band emission rate factor, J. Quant. Spectrosc. Radiat. Transfer, 9, 1593, 1969.
Phillips, L. F., and H. I. Schiff, Mass-spectrometer studies of atom reactions, I, Reactions in the atomic nitrogen-ozone system, $J$. Chem. Phys., 36, 1509, 1962.

Prasad, S. S., and D. R. Furman, Auroral electric field heating: Its implications in the altitude profile of ionic composition and emissions, J. Geophys. Res. 80, 3701, 1975.

Rusch, D. W., Satellite ultraviolet measurements of nitric oxide fluorescence with a diffusive transport model, J. Geophys. Res., 78 , $5676,1973$.

Rusch, D. W., and C. A. Barth, Satellite measurements of nitric oxide in the polar region, J. Geophys. Res., 80, 3719, 1975.

Rusch, D. W., A. I. Stewart, P. B. Hays, and J. H. Hoffman, The N I (5200 A) dayglow, J. Geophys. Res., 80, 2300, 1975.

Swider, W., and R. S. Narcisi, Ion composition of an IBC class II aurora, 2, Model, J. Geophys. Res., 79, 2849, 1974.

Torr, M. R., D. G. Torr, J. C. G. Walker, P. B. Hays, W. B. Hanson, H. H. Hoffman, and D. C. Kayser, Effects of atomic nitrogen on the nocturnal ionosphere, Geophys. Res. Lett., 2, 385, 1975.

Torr, M. R., R. G. Burnside, P. B. Hays, A. I. Stewart, D. G. Torr, and J. C. G. Walker, Metastable ${ }^{2} D$ atomic nitrogen in the midlatitude nocturnal ionosphere, J. Geophys. Res., 81, 531, 1976.

Vallance-Jones, A., Aurora, D. Reidel, Dordrecht, Netherlands, 1974.

Watson, C. E., V. A. Dulock, R. S. Stolarski, and A. E. S. Green, Electron impact cross sections for atmospheric species, 3, Molecular oxygen, J. Geophys. Res., 72, 3961, 1967.

Wilson, W. E., Rate constant for the reaction $\mathrm{N}+\mathrm{O}_{2} \rightarrow \mathrm{NO}+\mathrm{O}$, J. Chem. Phys., 46. 2017, 1967.

Winters, H. F., Ionic absorption and dissociation cross section for nitrogen, J. Chem. Phys., 44, 1472, 1966.

(Received June 4, 1976;

accepted October 18, 1976.) 